\title{
A Standard-Based Model For Adaptive E-Learning Platform For Mauritian Academic Institutions
}

\author{
P. Kanaksabee, University of Technology, Mauritius \\ M. P. Odit, University of Technology, Mauritius \\ A. Ramdoyal, University of Technology, Mauritius
}

\begin{abstract}
The key aim of this paper is to introduce a standard-based model for adaptive e-learning platform for Mauritian academic institutions and to investigate the conditions and tools required to implement this model. The main forces of the system are that it allows collaborative learning, communication among user, and reduce considerable paper work. Adaptation in the context of elearning is about creating a learner experience that purposely adjusts to various conditions over a period of time with the intention of increasing pre-defined success criteria. Adaptation requires the functionality to be able to interact with and manipulate data on the learning design, the users and the system, and its contents. Therefore, adaptation is not an add-on that can just be plugged into a learning environment. Each of the conditions for adaptation has to be represented in a rigorous way. We will introduce a model based on a set of key learning technology standards that enable a structured, integrated view on designing, using and validating adaptation.
\end{abstract}

Keywords: Adaptive e-learning and e-learning platform

\section{INTRODUCTION}

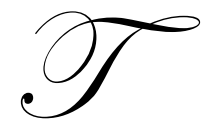

his paper analyses the e-learning approaches that can be implemented for academic institutions in Mauritius. It is one of the important initiatives that constitute the most significant attempt to address the needs of tertiary education in Mauritius. The need for making Mauritius a knowledge hub by the Mauritian Government to address the issues to academic institutions is the signal to move towards creating graduates with a good grounding in Information and Communication Technology (ICT) and other important areas. In particular, both the private and public universities began to include objectives designed to promote e-learning methodologies and multimedia skills. In this line, The University of Technology, Mauritius has taken the initiative in starting an e-learning platform for the program of Certification in Public Procurement. There is a general agreement across existing education literature that collaborative dialogue and communication with instructors and lecturers are major contributors toward successful learning. Nichols (2001) argues further that course design considerations (a variety of learning resources, opportunities for reflection and simulative interaction) are very important and proposes a course design framework within which technology can be made to work effectively.

Peter Van Rosmalen et al (2006) explained that adaptation in the milieu of e-learning is about creating a learner experience that purposely adjusts to various conditions (e.g. personal characteristics and interests, instructional design knowledge, the learner interactions, the outcome of the actual learning processes, the available content, the similarity with peers) over a period of time with the intention of increasing success for some pre-defined criteria that is effectiveness of e-learning. Adaptation focussed on one or more of the above mentioned conditions that has been on the e-learning research agenda for well over three decades in different research topics such as Intelligent Tutoring Systems Wenger (1987), Adaptive Hypermedia, (now Web-based adaptive educational systems), Brusolovsky (2001) and Multi-agent systems (Lin 2005; Ayala, 2003; Boticario et al., 2000) often based upon an Instructional Design model or guidelines, for example, Learning Styles by Felder \& Silverman (1988) and 
Concept Understanding Leshin et al., (1992) from which 'rules' are derived to implement the adaptation logic in an application specific representation.

This paper attempts to add to the existing literature by bringing new evidence on the E-Learning platform. The remainder of the paper is organized as follows. Section 2 provides a brief empirical review of the literature. Section 3 describes the operational feasibility. In section 4, we provide discussion on the dynamic E-Learning model. In section we discuss about the tools and techniques that have been used in this study and we conclude in section 6.

\section{EMPIRICAL REVIEW}

During the last decade remarkable progress has been made in conceptualizing, assessing and investigating the determinants of the social and psychological aspects of the learning environments of classroom and schools according to Fraser (1998). In this era of information explosion, providing the right information to the right person within an acceptable lapse of time is very important to boost productivity and efficiency. Thinking along those lines, many researchers tend to regard our educational system as a process which needs to be revisited. Many might argue that this channel of doing things has a proven track record but on the other hand we must also have an eye on the failures of the system.

A more significant feature of learning environment research is that the most productive learning outcomes are most likely to occur when learners perceive that their actual learning environment matches their preferred learning environment Yarrow (1997). M Nilsson et al, (2002) explained how E-learning is becoming nowadays one of the most interesting of the "e-"domains available through the Internet. Despite presenting favorable statistical figures of pass rates be it at primary, secondary, and tertiary level; however when deeply analyzed we can easily notice that not all factors were taken into consideration (e.g. dropout students, grading level, etc). One of the biggest drawback of the current teaching method is the under utilization of technologies to enhance learning experience by that we mean; its nearly inconceivable that each classroom of each institution be fitted with projectors and other amenities. However we should also consider the costs of implementing those facilities but there are many other cheap technologies on the market nowadays which could do an equally effective job. E learning systems are on great demand in the educational sector. Many scholar institutions are switching to this new learning strategy for a better organization of the work plan and greater communication between the learner and the tutor.

However E-learning is not only about browsing mechanism, a section of web links or a few online quizzes. Various e-learning projects implementation have been carried out and major conclusion has been derived after appropriate surveys have been carried out. One of the major concerns was how an e-learning platform could support students in different modes. In addition to this there is no proper sequential browsing of learning modules. More over the inability to provide mechanisms that would facilitate the exploration of knowledge according to specific learning needs was pointed out as a learning obstacle. From teacher's perspective there was a major difficulty at the reconstruction of learning material since there is a limitation in html pages linking. Additionally the content management constraints the creativity and does not support flexible learning scenarios. Finally the absence of learning templates or content templates proves a lack of learning orientation for certain e-learning platform. The major difficulty of the learners was the inability to find the appropriate learning content according to their previous experiences on the field. Eventually, there is the inability of the system to diagnose learners' needs and to deliver customized learning content. Moreover the inability of the systems to support knowledge management mechanisms such as web semantics proved a critical barrier for the achievement of performance

It has often been argued that E-learning is a waste of time only if we don't believe it as a value adding process that challenges the way of teaching. The vast majority of e-learning applications (Urdan and Weggen 2000) fail to establish a unique learning experience suitable for the learners' preferences. The static approach to learning content limits the willingness of many people to use ICT's in order to learn. Especially in academic environments the realization of e-learning usually is limited to the deployment of a well known e-learning platform such as WebCT, Blackboards, Learning Space etc, and the adaptation of learning content to the specific supported format for learning objects Rowley (2000). 
Bates (2001) describes e-learning as a field that is based on the locational aspects that is at one end there is 'no online learning,' in the case of face-to-face classroom teaching, and, at the other end, 'fully online learning,' in the case of distance education. In between these opposites, Bates considered a range of mixed learning approaches that are useful in understanding what e-learning has to offer.

Harasim et al. (1995) observed that e-learning is a valuable addition to the teaching and learning environment in the face-to-face classroom situation. They also noted that e-learning provided a good start for instructors wishing to explore the capacities of new technology in their teaching modes. Bates also describes the existence of a "mixed mode" application of e-learning in which there was a reduced degree of face-to-face teaching and an increased degree of online learning.

Much has been said about the importance of e-learning in promoting the use of IT in university teaching and preparing students for the new technologies that they will face in the job market. However, we first need a clear definition of e-learning. According to some authors, e-learning or electronic learning is a concept that associates learning with the application of new technologies to the learning process, namely the internet, intranet, email, satellite broadcasts, audio/video tape, or Compact Disc Read-Only Memory (CD-ROM). It occurs in a range of learning situations: web-based learning, computer-based learning and virtual classrooms (Clark \& Mayer, 2003, Rosenberg 2001, Selwyn \& Gorard 2003). This broad definition does not give a privileged place to web-based learning approaches.

Roziana (2006) observes that e-learning takes place in Malaysia in two forms: paperless and blended between paper-based and electronic based. However, she warned e-learning practitioners that the emphasis in elearning should not be on the 'e-'or the electronic gadget or technology but rather the ' 1 ', that is the learning. Supyan (2006) further supports that the use of internet technology such as online forum in e-learning should be based on sound pedagogical procedures and not technologically driven. Institutional, societal and political advantages do not automatically lead to better student learning. Eisenstadt and Vincent (2000) reserve the advantages of technology for those applications built on sound pedagogy: "Evidence continues to confirm that the Web, as with other technologies and media, can be successfully exploited provided that the educational need to which it is applied is identified first." Institutional, social and political expediencies may be helpful to justify e-Learning investment, but they are not sufficient on their own. There must also be a conviction that technological tools improve teaching and learning to ensure long-term commitment to their use, and to ensure appropriate implementation.

From the literature it can be deduced that change is inevitable if we are to meet tomorrow's challenges in the Mauritian education sector. However change can be done in several ways, many school of thoughts would inevitably disagree on many fundamental aspects of the various solution which we might opt to go with. The next section addresses the operational feasibility study which analyzes the different alternatives that exist to strengthen the Mauritian education system.

\section{OPERATIONAL FEASIBILITY STUDY}

Resource wise the study will not be demanding, since little maintenance would be required provided no major changes are made to the system. However when designing this system we would thrive to make it an application which would be institution independent and hence education system independent. This application is firmly capable of if not solving but ameliorate the issue of quality education in Mauritius. The answer to succeed in e-learning is high quality educational content. But producing (quality) educational content is difficult and time consuming. Hence, in order to simplify this process and assure its outcome quality, we propose to reuse previously existing educational content. Also, our intention is to increase learner motivation by providing tailored content adapted to his/her personal needs and, at the same time, to reduce time spent in training with the maximum benefit. The idea is to offer students a learning tool easy to use and capable of being adapted to the user's preferences. 


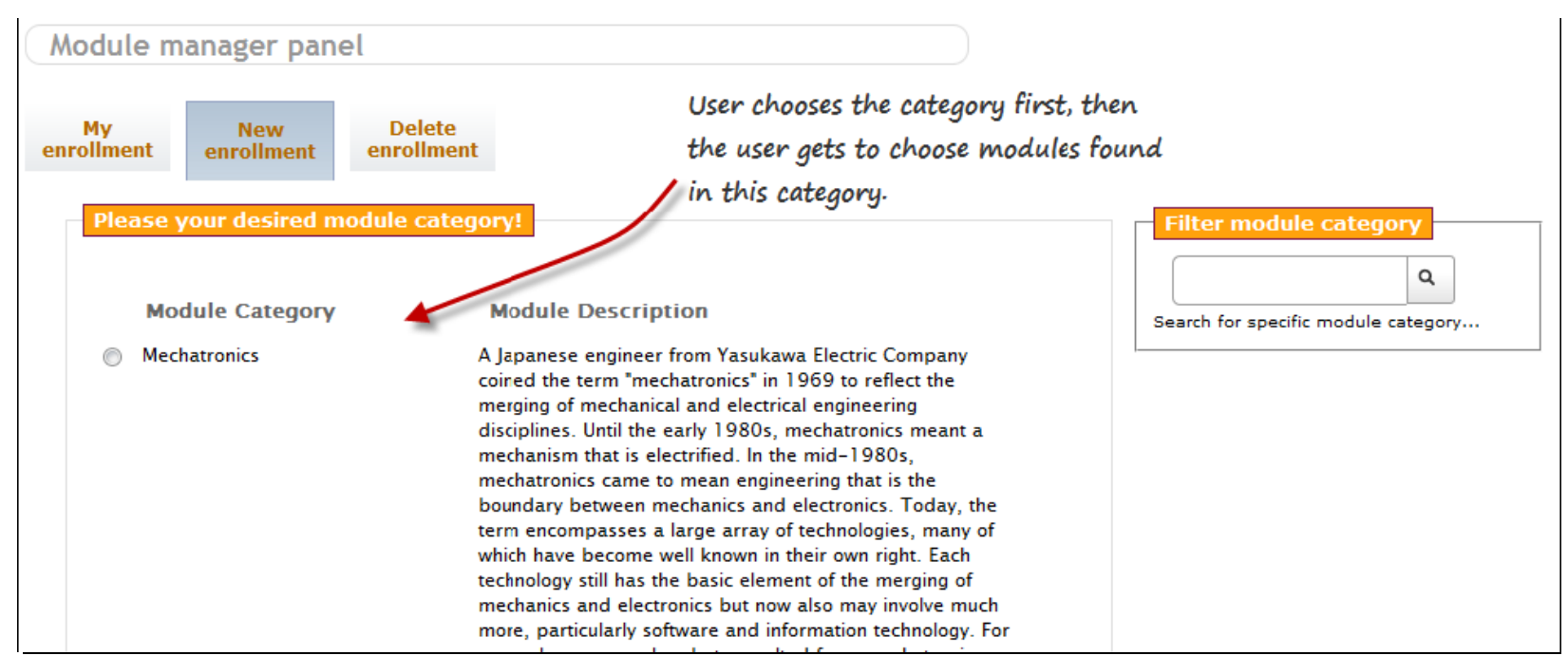

Figure 1: Enrol for new module

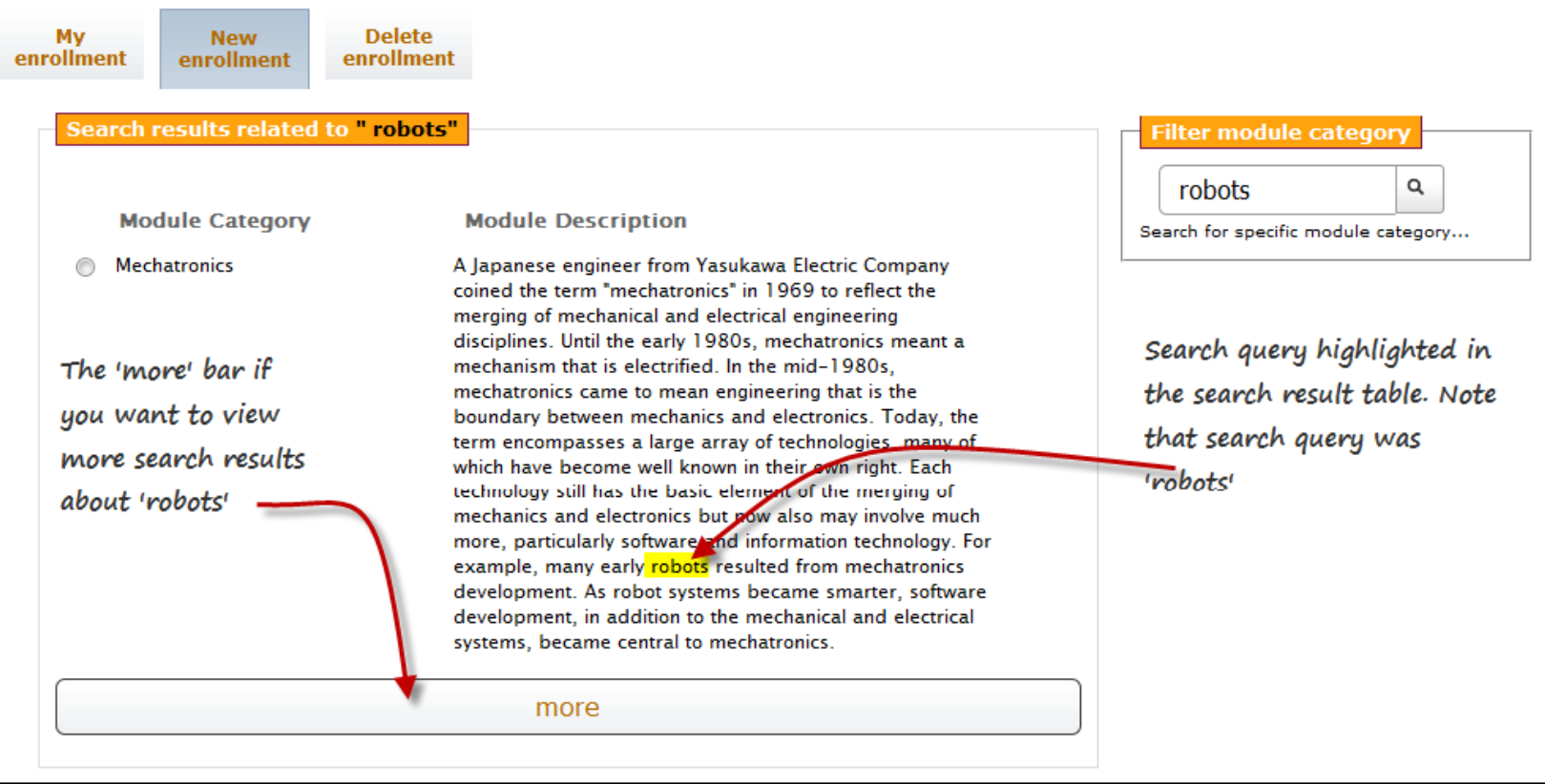

Figure 2: Search module category

\section{DYNAMIC E-LEARNING MODEL}

\section{System Overview}

The main functionalities of the system would be to enable functions such as creating, updating, deleting and managing courses, quiz, assignment and many other academic materials. Also the system would enable two way communications such as mails and also Social learning such as forums. It would also helps in complex find-ability of academic contents or any other material pertaining to the system. User generated contents such as posting news in the application. The system would cater for a blended approach that is give a sense of community whereby users can identify themselves, in other words each user would have their own customize profile. The platform has provision for diagrammatic reporting facilities about different statistical issues such as student performance, course 
registration, course completion, etc. Moreover the system would deliver appropriate material to different students based on their skills (such as elementary, basic and advance mode). The system would allow online submission of assignments and would be applicable in various scenarios as compared to the traditional mode of dispensing lectures.

\section{Module}

This feature is one of the core components in the system. Through this interface a user might create, manage and delete a module. Of course each of these mentioned actions would be made available depending on their role configuration. From an administrative level, it can be turned off completely or selective access might be granted to each user. As we have stated previously this feature is one of the core component in the system. Through this interface a user might create, manage and delete a module. From a student point of view, using this feature would enable the latter to manage his enrolment as well as participate in his enrolled modules.

\section{Prerequisite}

- $\quad$ The site owner should have enabled the feature cross site.

- $\quad$ The user should be registered and duly activated.

- $\quad$ The user role configuration should allow him to use this feature.

- $\quad$ From a student point of view, a user should be enrolled in a particular module for participation.

- From a tutor point of view, a user should have created at least one module to be able to carry out module management.

\section{Dependencies}

- User that is a user should first be created and activated.

- $\quad$ Enrolment that is a user should be duly enrolled with a module to be able to participate in the latter.

- Module that is a module must exist before a tutor can service it and a student can get enrolled in it.

\section{Assignment}

This feature is responsible for providing an interface for user to upload their assignment. From an administrative perspective, a tutor for example might use this interface to mark the submitted assignment. The site owner might choose the granularity of access by either allowing only submission of assignment or marking of assignment. We should note that assignments are presented to the user depending on their set criteria, that is, a user can get access to upload an assignment if the start and end date criterion are not violated. As mentioned before, this feature would be responsible for providing an interface for users to upload their assignment. From and administrative perspective, a tutor might use this interface to mark the submitted assignment.

From a user's perspective:

- The site owner should have enabled the feature cross-site.

- $\quad$ The user should be registered and duly activated.

- The user role configuration should allow him to use this feature.

- $\quad$ The user should be enrolled with at least one module.

- $\quad$ His activation status should be active vis-à-vis this module.

- The module creator should have created an assignment for that particular module.

- $\quad$ The start and end date criterion should not be violated.

- $\quad$ Once the assignment has been uploaded, the process cannot be repeated again.

From an Administrative Perspective:

- $\quad$ The site owner should have enabled the feature cross-site.

- The user should be registered and duly activated. 
- $\quad$ The user role configuration should allow him to use this feature.

- The user should have created at least one module

- $\quad$ At least one user should have uploaded his work for the tutor to mark.

Dependencies:

- User, a user should first be created and activated,

- $\quad$ Enrolment, a user should first be enrolled with a module to attempt assignment

Accessing the feature:

- User should log in the system

- $\quad$ Once the user reaches his workspace, the feature tab should be selected.

- User should select the assignment icon and clicks on the latter.

- $\quad$ The system would redirect the user to the assignment page.

Depending on their role configuration, the user would either get to upload an assignment or mark and assignment. In certain circumstances, a user might get both options but this would normally be for the site owner account.

User access:

When the user tries to upload an assignment, the upload assignment tab should be selected. The interface would be loaded with the module which the user is currently enrolled with. The user will then browse the different modules if any. If the user selects the 'signals and systems II' module for instance and there is an assignment whose start date and end date is not violated, the assignment is presented to the. If for instance, the user has already submitted the assignment, the arrow besides the label would be green. When the user selects this assignment, the system would present the user with his marks if any. Considering the case where the assignment has not yet been submitted, the arrow besides the assignment name would be yellow. When the user selects the assignment, the system would present an interface through which the work can be uploaded. Once the work has been submitted, no further submission is accepted.

\section{Administrative access:}

- When the tutor tries to mark the assignment, one of the created modules should be chosen.

- When the tutor has finally chosen a specific module, the assignment available for the particular module will be presented through the system.

- The tutor would then choose the assignments and upon selection, the system would load another interface.

- The tutor would then choose one of the created selected modules.

- When the tutor has finally chosen a specific module, the system would present the assignments available for that particular module.

- The tutor would then choose among the assignments and upon selection, the system would load another interface. In the newly created interface, the application will display all the submission from users pertaining to that assignment.

- The system would also indicate the number of expected submissions and the number of actual submission.

- $\quad$ The tutor can then choose a specific student submission and choose to view more.

- Once the tutor has made a selection, all the details about the assignments (for example, date posted, date attempted) would be available. The tutor would also get to see the both the user's answer and the right answer. Through the provided interface, the user can fill the marks to allocate to the specific user. Some more guidance can also be provided by the tutor to the student through the WYSIWG editor.

- To complete the process, the tutor needs to hit the mark assignment tab and the students' marks are updated. 


\section{Question}

This feature is responsible for providing an interface for registered and authorized user to mark questions attempted by the students. From there the tutor for instance would be able to mark each assignment and even leave a small feedback on the student performance.

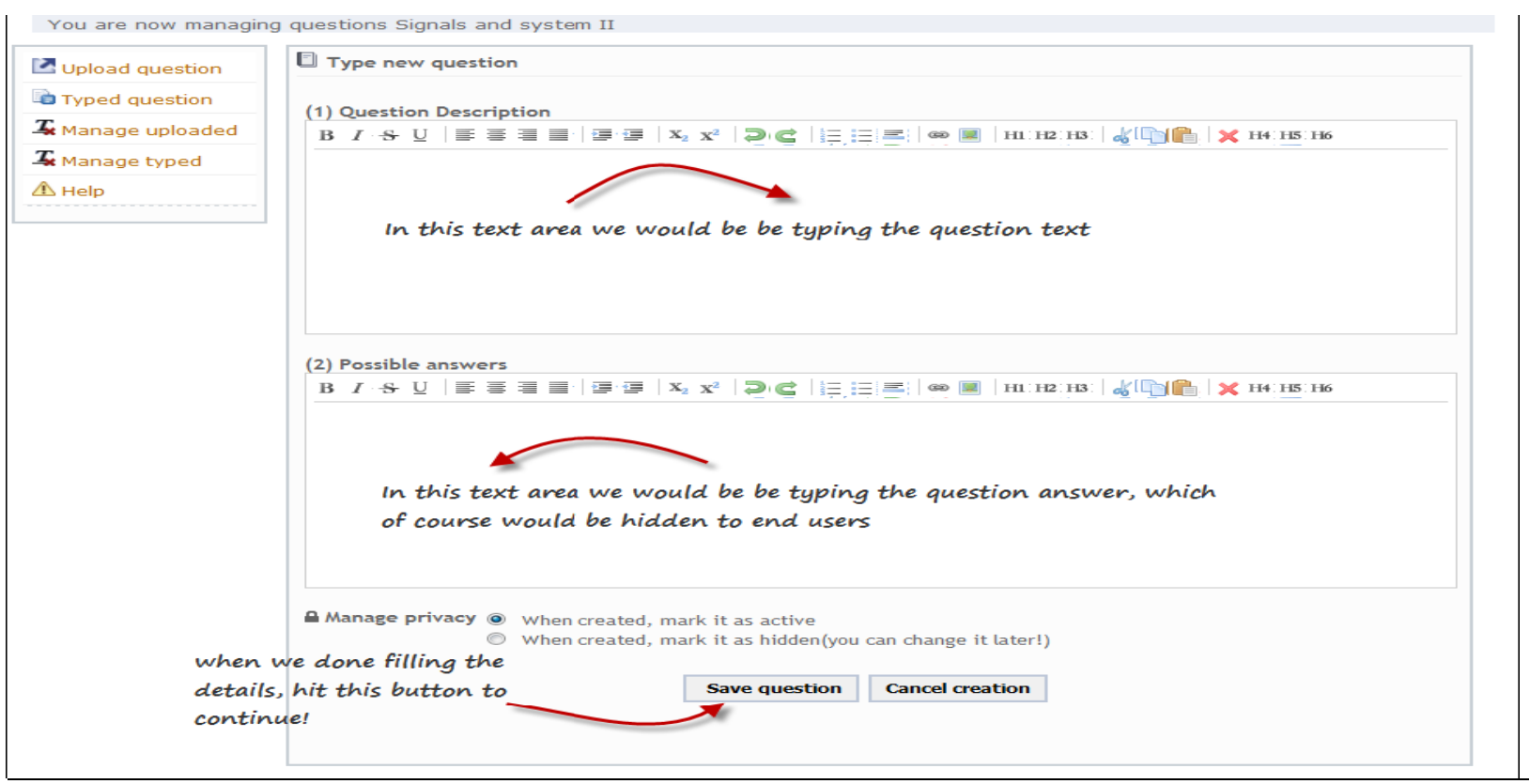

Figure 3: Create a new Question

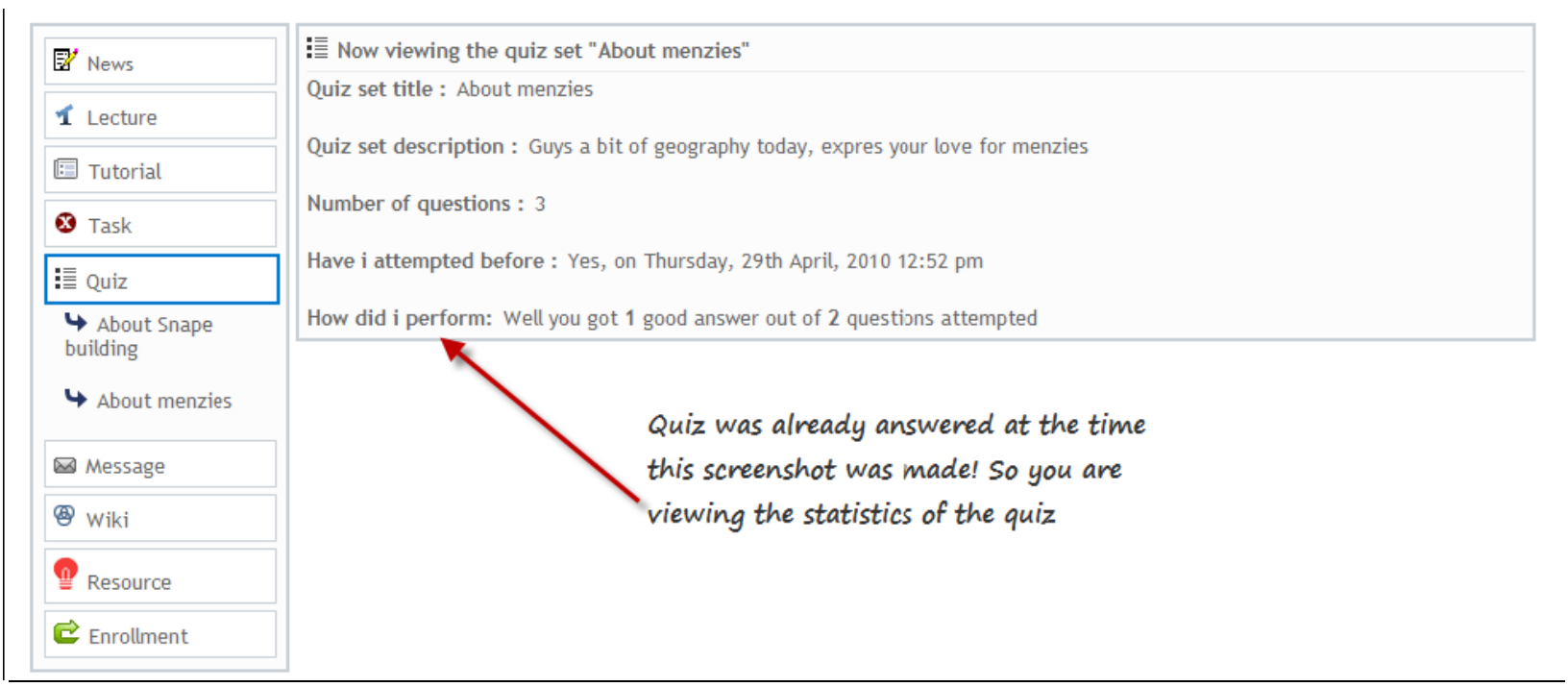

Figure 4: Create a new Quiz 


\section{TOOLS AND TECHNIQUES}

The tools used in software quality assurance are generally testing tools wherein an application is run through a series of tests to gauge the performance of the application The tools used in these tests vary in purpose and performance. These applications range from testing the code or running the application under great stress. These tools are employed to test the application and produce numbers and statistics regarding the actual application. Through these numbers, we as developers will know if the application has lived up according to the targeted performance. Naturally for each application being developed, each would have a range of testing tools which would be appropriate to used and of course it also depends on the personal choice of the developer. In our case we have listed a set of tools which we happen to use quite frequently in our testing endeavours. No doubt, these testing software on their own are not sufficient to guarantee a high quality of work, some rigorous ethics should also be present to guarantee a software offering a reasonable quality of service. In table 1, we have listed a few techniques which we would employ in our project to boost quality assurance.

Table 1: Tools \& techniques

\begin{tabular}{|c|c|}
\hline \multicolumn{2}{|r|}{ Tools } \\
\hline Names & Description \& Purpose \\
\hline Bugzilla & $\begin{array}{l}\text { Developed by Mozilla, this open source testing tool works as the name suggests. } \\
\text { Bugzilla specializes in detecting bugs found in the application or website. Since the } \\
\text { application is open-source it can be used freely and it is availability in different OS } \\
\text { makes it even a viable alternative for error tracking. The only downside is it has a long } \\
\text { list of requirements before it could run. This tool would mainly be used to detect flaws } \\
\text { in the markup languages and help use comply with the W3C standards and valid } \\
\text { XHTML protocols. }\end{array}$ \\
\hline Xdebug - debugger and profiler tool & $\begin{array}{l}\text { Xdebug is a PHP extension that helps you debug and profile scripts. The profiling } \\
\text { functionality is particularly useful. The profiler uses a common output file format, } \\
\text { allowing you to use tools like KcacheGrind to quickly find bottlenecks in your code. A } \\
\text { good profiler is an essential tool for any serious developer, as it allows you to properly } \\
\text { optimize your code while avoiding the hazards of premature optimization. }\end{array}$ \\
\hline PhpMyAdmin & $\begin{array}{l}\text { PhpMyAdmin is one of the most useful administrative tools available for any database } \\
\text { (along with it's PostgreSQL and SQLite cousins phpPgAdmi nand phpSQLiteAdmin). } \\
\text { It's useful for everything from constructing and altering databases to debugging } \\
\text { applications and making backups. }\end{array}$ \\
\hline \multicolumn{2}{|r|}{ Techniques } \\
\hline Names & Description \& Purpose \\
\hline Defect reporting and tracking & $\begin{array}{l}\text { For reporting and resolving defect in a deliverable whether it is a document or code, we } \\
\text { will be maintaining an excel sheet "Defects.xls" which will enlist defects with } \\
\text { description, phase detected, person responsible ( for solving, testing and closing), date } \\
\text { opened, date closed. }\end{array}$ \\
\hline Controlled product release & $\begin{array}{l}\text { Choose a limited number of users to create a beta testing of the application. It generally } \\
\text { helps to identify bugs which are generally not obvious to spot on. }\end{array}$ \\
\hline
\end{tabular}

\section{CONCLUSION}

The software quality management processes must address how well software products will, or do, satisfy customer and stakeholder requirements, provide value to the customers and other stakeholders, and provide the software quality needed to meet software requirements. The application is designed in such a way that it can be easily ported and configured to be used in practically every academic institution in Mauritius. This means that no "site values" should be hard coded but instead should be dynamic and can be changed at any point in time without major difficulties. The course content within the system can be adapted and customized by any stakeholders / users. Data privacy will be given prime importance that is we will make sure that users can only access information and sections of the application which they are allowed to. The study enable designers, tutors and learners to make the most effective use of the systems while at the same time guaranteeing a system committed to a complex set of standards and a variety of adaptive learning scenarios. The way forward would be to implement such system at the 
primary, secondary and tertiary level in the Mauritian education system to standardized teaching and learning strategies .

\section{AUTHOR INFORMATION}

P. Kanaksabee is a full-time lecturer at the Department of Business Informatics and Software Engineering, University of Technology, Mauritius (UTM). He holds an MSc Computing and Information Systems from the University of Greenwich, London and a BA Mathematics from University of Mumbai, India. He is a board member of the Academic council and has been a Quality auditor at UTM. He has also been a member of the British Computer Society and an associate member of the Institute of Mathematics and its Applications. His area of research includes programming for the web, E-services and E-learning systems.

M.P Odit is a full-time lecturer at the University of Technology, Mauritius (UTM). He received his MPhil degree from UTM. He holds the degrees of MBA and BCom from Pune University, India. He is Officer in Charge of the Dept of Public Policy and Management, School of Business Management and Finance, UTM. He has authored/Coauthored in several journals and his area of research includes corporate investment, financial leverage, risk management economic growth, reform in taxation and education.

A. Ramdoyal is currently under a research assistant contract at the University of Technology, Mauritius (UTM). He holds a Bachelor's Degree in Software Engineering from University of Technology, Mauritius.

\section{REFERENCES}

1. Bates, T. (2001). National Strategies for E-learning in Post-secondary Education. Paris: UNESCO: International Institute for Educational Planning.

2. Boticario, J. G., Gaudioso, E., \& Hernandez, F. (2000). Adaptive Navigation Support and Adaptive Collaboration Support in WebDL. Lecture Notes in Computer Science, 1892, 51-61.

3. Brusilovsky, P. (2001). Adaptive Hypermedia. User Modelling and User-Adapted Interaction, 11, 87-110.

4. Clark, R. C., \& Mayer, R. E. (2003). e-Learning and the Science of Instruction. San Francisco: Pfeiffer.

5. Eisenstadt, M., \& Vincent, T. (2000). The knowledge web: Learning and collaborating on the Net, UK: Kogan Page.

6. $\quad$ Felder R. M., \& Silverman L. K. (1988) Learning and teaching styles in engineering education. Engineering Education, 78, 674-681.

7. Harasim, L., Hiltz, S. R., Teles, L., \& Turoff, M. (1995). Learning Networks: A Field Guide to Teaching and Learning Online. Cambridge: The MIT Press.

8. Leshin, C., Pollock, J., \& Reigeluth, C. (1992). Instructional Design Strategies and Tactics, NJ, USA: Educational Technology Publications.

9. Lin, F. O. (2005). Designing Distributed Learning Environments with Intelligent Software Agents, London: Information Science Publishing.

10. Nichols, M. (2001). Teaching for learning, Palmerston North: TrainInc.co.nz.

11. Rosenberg, M. J. (2001). E-Learning: Strategies for Delivering Knowledge in the Digital Age. New York: McGraw-Hill.

12. Rowley, J. (2000). "Is higher education ready for knowledge management?” International Journal of Educational Management 14(7): 325-333.

13. Roziana Mohd Rosli (2006). Language pedagogy in Online Teaching at the institutes of Higher Learning in Malaysia. Masters Thesis. Bangi: UKM

14. Selwyn, N., \& Gorard, S. (2003). Reality Bytes: Examining the Rhetoric of Widening Educational Participation via ICT. British Journal of Educational Technology, 34(2), 169-181.

15. Supyan Hussin (2006). Online Forum in ELT training program: Constraints or Problems? Proceedings for 6 Annual Southeast Asian Association for Institutional Research SEEAIR 2006 Conference. Transforming Higher Education for Knowledge Society. Kuala Lumpur: OUM.

16. Urdan, T. and C. Weggen (2000). Corporate e-learning: Exploring a new frontier, WR Hambrecht \& Co.

17. Van Rosmalen, P., Vogten, H., Van Es, R., Passier, H., Poelmans, P., \& Koper, R. (2006). Authoring a full life cycle model in standards-based, adaptive e-learning. Educational Technology \& Society, 9 (1), 72-83. 
18. Yarrow A., Millwater, J. \& Fraser, B.J. (1997). Improving university and primary school classroom environments through preservice teachers' action research. International Journal of Practical Experiences in Professional Education, (1), 68-93.

\section{NOTES}

